\title{
MEASUREMENT OF SYSTEM COORDINATION DEGREE OF CHINA NATIONAL SUSTAINABLE COMMUNITIES
}

\author{
J.X. WU, X.M. WANG*, X. WANG \& W.J. PENG \\ School of Civil Engineering and Mechanics, Huazhong University of Science and Technology, China.
}

\begin{abstract}
Local governments in China have been presented with an opportunity to become more sustainable through the program of China National Sustainable Communities (CNSCs). This program is aimed at guiding CNSCs toward sustainable development among resources, economy, environment and society. This article is focused on coordinated development patterns of CNSCs, in which the integrated coordination of CNSCs was analyzed. The entire process of the coordinated development of CNSCs being taken as object of study, the concept of coordination degree for CNSCs was proposed and a coordination degree evaluation system framework for CNSCs was built, which was divided into four subsystems, namely resource, economic, environment and social subsystems. Furthermore, a coordination degree evaluation indicator system for CNSCs was set up and the index weight was calculated based on component importance with the method of Principal Components Analysis used for data analysis. Finally, an evaluation model for coordination degrees of CNSCs was established. Besides, a hierarchy for coordination degrees to evaluate sustainable development levels was also set up. For application of the proposed model and the hierarchy for coordination degrees of CNSCs, two national sustainable communities, Chengmai county and Baisha county in Hainan Province, were analyzed for case study.
\end{abstract}

Keywords: China National Sustainable Communities, construction, coordination degree, evaluation.

\section{INTRODUCTION}

The traditional pattern of industrialization and urbanization in China, characterized by high input, consumption and emission, is not able to meet the needs of development. There is an urgent demand to explore new development patterns, which can help achieve coordinated development among resources, economy, environment and society. As a practice of sustainable development strategies in China, the program of China National Sustainable Communities (CNSCs) has received increasing concerns from governments and experts.

In 1986, CNSCs was introduced by the government of China as a national program for comprehensive demonstration of sustainable development. This program is aimed at exploring mechanisms and patterns for coordinated development among resources, economy, environment and society in different types of regions and providing demonstrations for implementation of sustainable development strategies [1, 2]. It allows mechanism innovation and decision making by local governments, combined with local characteristics, to correct and reduce contradiction and incongruity in the process [3].

Sustainable development is a crucial and necessary choice for China. As a sustainable development demonstration, the program of CNSCs has achieved an increasingly significant progress over 30 years. By 2015, the program of CNSCs has already developed into an enormous network platform for sustainable communities with 189 CNSCs distributed in 31 provinces and 145 cities in China. Figure 1 shows the geographical distribution of CNSCs.

China is exploring theory and practice actively in the fields of addressing urban climate change and sustainable development [4]. Based on the characteristics of China, experts 


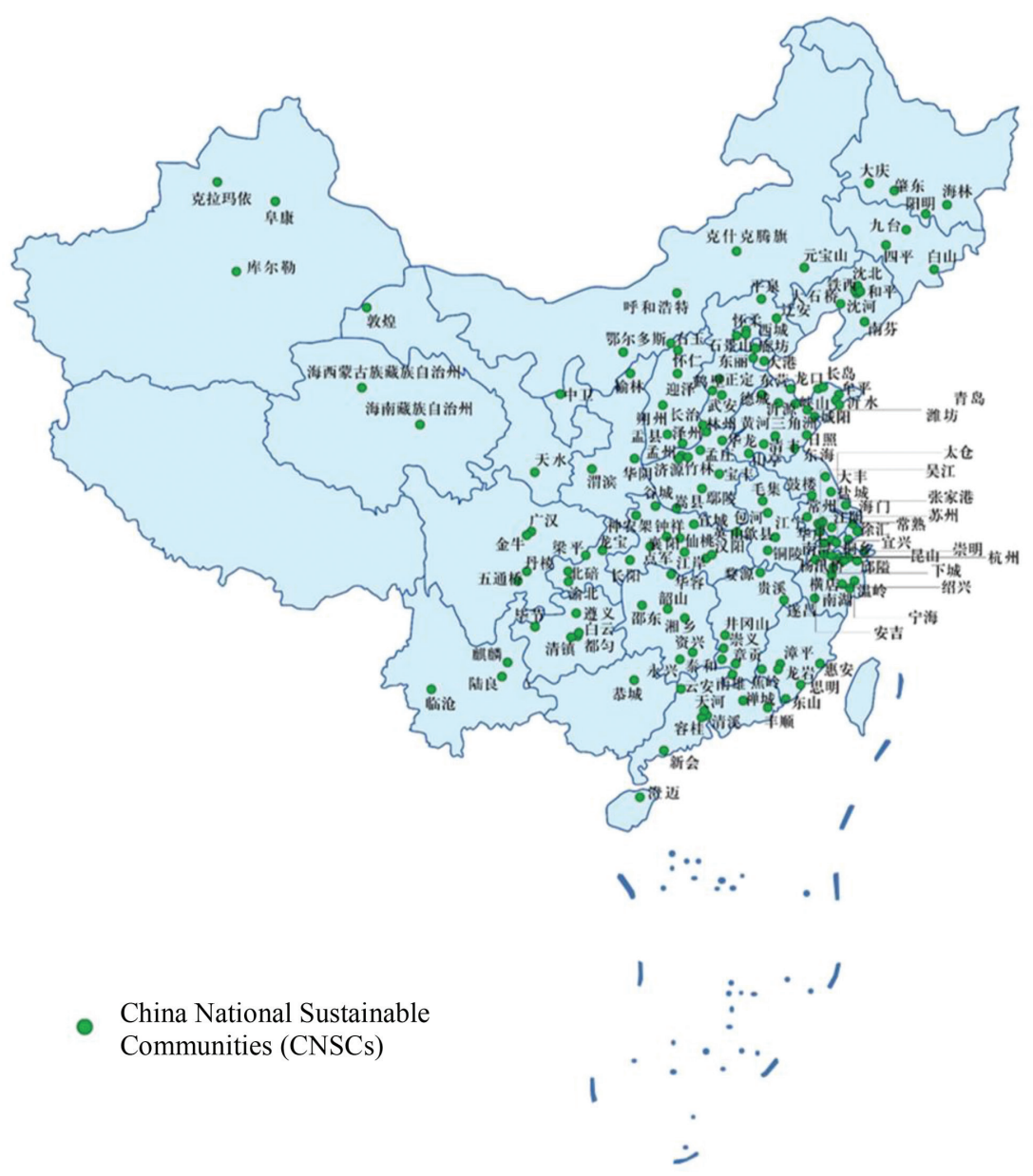

Figure 1: Distribution of CNSCs in China.

conducted extensive related research from perspectives of urban planning, building design, transportation planning and social participation $[5,6]$. Some practical theories and technologies applied to China were presented, which provided theoretical and technical supports for the planning and construction of CNSCs. Monitoring and evaluating the status and degree of sustainable development were not only the basis for integrated decision-making and coordination management mechanism of sustainable development but also the foundation for implementation of sustainable development strategies [7]. Coordinated development is the core content of sustainable development and the evaluation of coordination degrees is applicable to the sustainable assessment of urban ecological systems and economic systems [8]. The research on coordinated development mechanisms and evaluation methods for coordination degrees of CNSCs contributes to tackling sustainable-related problems in China. 


\section{METHODOLOGY}

\subsection{Definition of Coordination Degree and Technical Route for Evaluation}

Coordination refers to the harmonious and virtuous-cycle relationship between two or more kinds of subsystems or elements in a system [9]. Coordinated development refers to an evolution process from junior to senior, from simplicity to complexity or from disorder to order based on the harmonious and virtuous-cycle relationship between subsystems or elements in a system [10]. Consequently, the system coordination of CNSCs refers to an orderly state, characterized by sustainable utilization of resources, sustainable growth of economy, sustainable improvement of environment and sustainable development of society, which can be achieved by reaching the coordination status among the subsystems of resources, economy, environment and society or elements of a system in the process of development and evolution.

Sustainability is a continuous optimization process with the change of economy, society and environment rather than a fixed state [11]. From the angle of system theory, sustainable development refers to development at a higher level, which is based on coordinated development of subsystems of resources, economy, environment and society [12]. CNSCs become the carrier of sustainable development. In the development process of CNSCs, sustainable utilization of resources, sustainable growth of economy, sustainable improvement of environment and sustainable development of society play important roles. Therefore, sustainable communities are defined as an open system made up of four subsystems, namely resource subsystem, economy subsystem, environmental subsystem and social subsystem. The four subsystems influence and interact with each other, jointly promoting the improvement and optimization of sustainable communities constantly.

Coordination degree, reflecting the harmony degree among subsystems or elements in a system in the development process and the tendency of systems from disorder to order, is taken as a quantitative index to evaluate system coordination [13]. The coordination degree of CNSCs refers to the degree of harmony reached through coupling relationship between subsystems (i.e. coordination of various subsystems) in the construction process of CNSCs. The calculation of system coordination of CNSCs includes four stages. At the first stage, the evaluation index reflecting the development level of CNSCs is established. Next, the method of Principal Component Analysis (PCA) is used to determine the weight of indicators. Measurement of the development level for all subsystems and their coordination is the main priority at the third stage. Finally, the system coordination degree of CNSCs is computed based on all our previous work.

\subsection{Evaluation index for coordination degrees of CNSCs}

Based on the 'construction and planning index system of CNSCs' [2] issued by the Administrative Center for China's Agenda 21 and the 'innovation capability evaluation index system of CNSCs' [14, 15] issued by Department of Social Development of Ministry of Science and Technology, we proposed the coordination degree evaluation index system (Table 1) through index selection and improvement. Here, the new evaluation index system of CNSCs was divided into four subsystems: that is, resources subsystem $\left(\mathrm{B}_{1}\right)$, economic subsystem $\left(B_{2}\right)$, environmental subsystem $\left(B_{3}\right)$ and social subsystem $\left(B_{4}\right)$. 
Table 1: Evaluation index system of CNSCs.

\begin{tabular}{|c|c|c|}
\hline Objective & Subsystems & Index \\
\hline \multirow{21}{*}{$\begin{array}{l}\text { A: Coordination } \\
\text { degree of CNSCs }\end{array}$} & \multirow{6}{*}{$\begin{array}{l}\mathrm{B}_{1}: \text { Resources sub- } \\
\text { system }\end{array}$} & $\mathrm{C}_{101}:$ Population family planning rate $(\%)$ \\
\hline & & $\mathrm{C}_{102}:$ Natural population growth rate $(\%)$ \\
\hline & & $\mathrm{C}_{103}:$ Forest coverage $(\%)$ \\
\hline & & $\begin{array}{l}\mathrm{C}_{104}: \text { Per capita area of cultivated farmland } \\
\text { (acres) }\end{array}$ \\
\hline & & $\begin{aligned} \mathrm{C}_{105} & \text { : Energy consumption amount per unit } \\
& \text { output value of ten thousand Yuan(tons } \\
& \text { of standard coal equivalent, TCE) }\end{aligned}$ \\
\hline & & $\begin{aligned} \mathrm{C}_{106}: \text { Water consumption amount per unit } \\
\text { output value of ten thousand Yuan (ton) }\end{aligned}$ \\
\hline & \multirow{6}{*}{$\begin{array}{l}\mathrm{B}_{2}: \text { Economic } \\
\text { subsystem }\end{array}$} & $\mathrm{C}_{201}:$ Annual growth rate of GDP $(\%)$ \\
\hline & & $\mathrm{C}_{202}:$ Per-capita GDP (ten thousand yuan) \\
\hline & & $\begin{array}{l}\mathrm{C}_{203} \text { : Locally budgetary revenue growth rate } \\
(\%)\end{array}$ \\
\hline & & $\begin{array}{c}\mathrm{C}_{204}: \text { Proportion of GDP accounted for by } \\
\text { added value of the tertiary industry }(\%)\end{array}$ \\
\hline & & $\begin{array}{c}\mathrm{C}_{205}: \text { Per-capita disposable income of urban } \\
\text { households (yuan) }\end{array}$ \\
\hline & & $\begin{array}{c}\mathrm{C}_{206}: \text { Per-capita net income of rural residents } \\
\text { (yuan) }\end{array}$ \\
\hline & \multirow{6}{*}{$\begin{array}{l}\mathrm{B}_{3}: \text { Environmental } \\
\text { subsystem }\end{array}$} & $\begin{array}{c}\mathrm{C}_{301}: \text { Standard discharge rate of industrial } \\
\text { wastewater }(\%)\end{array}$ \\
\hline & & $\mathrm{C}_{302}:$ Treatment rate of domestic sewage (\%) \\
\hline & & $\begin{array}{c}\mathrm{C}_{303}: \text { Standard discharge rate of industrial } \\
\text { gases }(\%)\end{array}$ \\
\hline & & $\begin{array}{l}\mathrm{C}_{304}: \text { Comprehensive utilization rate of indus- } \\
\text { trial solid waste }(\%)\end{array}$ \\
\hline & & $\begin{array}{l}\mathrm{C}_{305}: \text { Treatment rate of household garbage } \\
(\%)\end{array}$ \\
\hline & & $\begin{array}{c}\mathrm{C}_{306}: \begin{array}{l}\text { Per-capita green area of public places } \\
\text { (square meter) }\end{array}\end{array}$ \\
\hline & \multirow{3}{*}{$\begin{array}{l}\mathrm{B}_{4}: \text { Social } \\
\text { subsystem }\end{array}$} & $\begin{array}{l}\mathrm{C}_{401}: \text { Registered urban unemployment rate } \\
(\%)\end{array}$ \\
\hline & & $\mathrm{C}_{402}:$ Utilization rate of tap water $(\%)$ \\
\hline & & $\begin{array}{c}\mathrm{C}_{403}: \text { Coverage rate of old-age insurance for } \\
\text { urban workers }(\%)\end{array}$ \\
\hline
\end{tabular}

(Continued) 


\begin{tabular}{|c|c|c|}
\hline Objective & Subsystems & Index \\
\hline & & $\begin{array}{c}\mathrm{C}_{404}: \text { Coverage rate of social old-age insur- } \\
\text { ance for farmers }(\%)\end{array}$ \\
\hline & & $\begin{array}{l}\mathrm{C}_{405}: \text { Number of health workers per thousand } \\
\text { population (person) }\end{array}$ \\
\hline & & $\mathrm{C}_{406}:$ Cable TV coverage of the population $(\%)$ \\
\hline & & $\mathrm{C}_{407}$ :Aeonatal mortality rate $(\% o)$ \\
\hline & & $\mathrm{C}_{408}:$ Crime rate $(\%)$ \\
\hline & & $\begin{aligned} & \mathrm{C}_{409} \text { Proportion of fiscal expenditure } \\
& \text { accounted for by triple expenses } \\
& \text { concerned about science and } \\
& \text { technology }(\%)\end{aligned}$ \\
\hline & & $\begin{aligned} & \mathrm{C}_{410}: \text { Proportion of every ten thousand popu- } \\
& \text { lation accounted for by college degree or } \\
& \text { above population }(\%)\end{aligned}$ \\
\hline & & $\begin{array}{c}\mathrm{C}_{411} \text { : Proportion of fiscal expenditure account- } \\
\text { ed for by education spending }(\%)\end{array}$ \\
\hline & & $\begin{array}{c}\mathrm{C}_{412}: \text { Illiteracy rate among young and } \\
\text { middle-aged people }(\% o)\end{array}$ \\
\hline
\end{tabular}

The data need to be normalized by eqn (1).

$$
Z_{i j}=\frac{X_{i j}-m_{j}}{S_{j}}
$$

where $X_{i j}$ refers to the original value of Index $\mathrm{j}, m_{j}$ refers to the average value of Index $\mathrm{j}$ in a selected period of time and $S_{j}$ refers to the standard deviation of Index $\mathrm{j}$.

In addition, the conditions $w_{j}^{k} \geq 0, \sum_{j=1}^{n_{k}} w_{j}^{k}=1$ needs to be met, where $w_{j}^{k}$ refers to the weight of Index $\mathrm{j}$ in System k calculated by the method of PCA.

Some parameters, such as characteristic value, variance contribution rate and accumulated variance contribution rate of components, need to be computed, and the components with their accumulated variance contribution rates more than $90 \%$ are recognized as principal components. Then, the variance contribution rates of principal components are used to obtain the coefficient of indexes in linear combination. After normalization, the weight of indexes is calculated.

Equation (2) is used to calculate the development level of four subsystems, namely resources (re), economy (ec), environment (en) and society (so).

$$
S D_{k}=\sum_{j=1}^{n_{k}} w_{j}^{k} z_{j}^{k}, k \in\{r e, e c, e n, s o\}
$$


Table 2: Five levels of coordination degree for CNSCs $(U)$.

\begin{tabular}{l|ccccc}
\hline $\begin{array}{l}\text { Coordination } \\
\text { degree }(U)\end{array}$ & $0.00-0.20$ & $0.21-0.40$ & $0.41-0.60$ & $0.61-0.80$ & $0.81-1.00$ \\
$\begin{array}{l}\text { Coordination } \\
\text { level }\end{array}$ & $\begin{array}{c}\text { Serious } \\
\text { imbalance }\end{array}$ & $\begin{array}{c}\text { Medium } \\
\text { imbalance }\end{array}$ & $\begin{array}{c}\text { Basic } \\
\text { coordination }\end{array}$ & $\begin{array}{c}\text { Good } \\
\text { coordination }\end{array}$ & $\begin{array}{c}\text { Excellent } \\
\text { coordination }\end{array}$ \\
\hline
\end{tabular}

where $S D_{k}$ refers to the development level of System $\mathrm{k}$ and $w_{j}^{k}$ refers to the weight of Index $\mathrm{j}$ in System k.

Equation (3) is used to calculate the coordination degree between all subsystems.

$$
U_{i j}=1-\frac{\left|S D_{i}-S D_{j}\right|}{\max \left(S D_{i}, \mathrm{SD}_{\mathrm{j}}\right)}, 0 \leq U_{i j} \leq 1, i, j=1 \cdots 4, i \neq j
$$

where $U_{i j}$ refers to the coordination degree between System i and System j, $0 \leq U_{i j} \leq 1$.

The formula for the coordination degree for the sustainable development of CNSCs is expressed in eqn (4):

$$
U=\frac{1}{6} \sum_{i=1}^{3} \sum_{j=i+1}^{4} U_{i j}
$$

where $U$ refers to the coordination degree for the sustainable development of CNSCs, $0 \leq U_{i j} \leq 1$.

If the development level of four subsystems (resources, economic, environmental and social) tends to be in harmony, the coordination degree of CNSCs $(U)$ is in a higher level; on the contrary, if the development level of four subsystems tends to be imbalance, the coordination degree of CNSCs (U) is in a lower level. When four subsystems tends to be perfect coordinate, $U=1$; on the contrary, once four subsystems tends to be completely uncoordinated, $U=0$. Based on the principle of clustering analysis and five-level grading method [16], the coordination degrees of CNSCs $(U)$ are divided into five levels (Table 2).

\section{DATA PROCESSING}

\subsection{Data sources}

The sustainable communities in Chengmai County and Baisha County of Hainan Province were taken for case study on the coordination degree of CNSCs. Chengmai County and Baisha County were approved as national sustainable communities in 2013 and 2014, respectively, and have received extensive attention from experts for their uniqueness of tropical islands. Commissioned by the Department of Science and Technology of Hainan province, our team from Huazhong University of Science and Technology prepared the construction plan for the sustainable communities in Chengmai County and Baisha County.

Chengmai County is located in the northwest of Hainan Island with $114.33 \mathrm{~km}$ of coastline and abundant ecological and historical resources. Baisha County is a typical minority autonomous county located in the west center of Hainan Island. Table 3 shows the construction status of the sustainable communities in Chengmai County and Baisha County.

All related data are from 'Construction Plan of National Sustainable Community of Chengmai County (2012-2016)' [17] and 'Construction Plan of National Sustainable Community 
Table 3: Construction status of sustainable communities in Chengmai County and Baisha County.

\begin{tabular}{|c|c|c|}
\hline Item & Chengmai County & Baisha County \\
\hline Subject & $\begin{array}{l}\text { Development of ecological indus- } \\
\text { tries and improvement of urban and } \\
\text { rural livelihood at the county scale } \\
\text { in the tropical island area of China }\end{array}$ & $\begin{array}{l}\text { Protection of resources and environ- } \\
\text { ment in ecological core areas, inheri- } \\
\text { tance of the Li nationality culture and } \\
\text { improvement of people's livelihood in } \\
\text { the tropical island area of China }\end{array}$ \\
\hline Objective & $\begin{array}{l}\text { Ecological county } \\
\text { New industrialized county } \\
\text { Leisure and low-carbon tourism } \\
\text { county } \\
\text { Demonstration base of high-effi- } \\
\text { ciency tropical agriculture }\end{array}$ & $\begin{array}{l}\text { Intensive ecological agriculture base } \\
\text { Processing and trade base of green } \\
\text { agricultural and forestry products } \\
\text { Leisure and longevity preservation } \\
\text { tourism resort } \\
\text { Demonstration area of ecology protec- } \\
\text { tion }\end{array}$ \\
\hline Priority & $\begin{array}{l}\text { Ecological agriculture } \\
\text { New industries } \\
\text { Low-carbon tourism industry } \\
\text { People's livelihood }\end{array}$ & $\begin{array}{l}\text { Protection of environment and natural } \\
\text { resources } \\
\text { Tropical eco-agriculture } \\
\text { Ecological tourism industry } \\
\text { Social issues and people's livelihood } \\
\text { Protection and inheritance of Li nation- } \\
\text { ality culture }\end{array}$ \\
\hline
\end{tabular}

of Baisha County (2014-2018)' [18]. The planned construction period for the sustainable communities in both counties is 5 years, and the base year for index calculation was 2011 and 2013, respectively.

\subsection{Results from model}

\subsubsection{Data analysis}

By the method mentioned in Section 2, the program SPSS v19.0 was used to process the data from the national sustainable communities in Chengmai County and Baisha County from 2011 to 2018. Table 4 illustrates the weight of all indexes.

\subsubsection{Calculation of coordination degrees}

Equation (2) was applied to calculate the levels of sustainable development for all subsystems with the results shown in Table 5.

Equation (3) was applied to calculate the coordination degrees among all subsystems with results shown in Table 6.

The results show that the coordination degree for the sustainable community of Chengmai County in 2011 is 0.531 , which belongs to the level of Basic Coordination according to Table 2, whereas the coordination degree of the sustainable community of Baisha County in 2013 is 0.650, which belongs to the level of Good Coordination. Although Chengmai County was better than Baisha County in the aspects of economic foundation and resources, Chengmai County was worse in system coordination of development. 
Table 4: Component matrix.

\begin{tabular}{|c|c|c|c|c|c|c|c|c|c|}
\hline \multirow{2}{*}{ Index } & \multicolumn{2}{|c|}{ Integrated score } & \multicolumn{2}{|c|}{ Weight } & \multirow{2}{*}{ Index } & \multicolumn{2}{|c|}{ Integrated score } & \multicolumn{2}{|c|}{ Weight } \\
\hline & Chengmai & Baisha & Chengmai & Baisha & & Chengmai & Baisha & Chengmai & Baisha \\
\hline $\mathrm{C}_{101}$ & 0.899 & 0.899 & 0.243 & 0.243 & $\mathrm{C}_{304}$ & 0.900 & 0.900 & 0.167 & 0.167 \\
\hline $\mathrm{C}_{102}$ & -0.902 & -0.902 & 0.013 & 0.013 & $\mathrm{C}_{305}$ & 0.885 & 0.885 & 0.166 & 0.166 \\
\hline $\mathrm{C}_{103}$ & 0.902 & 0.902 & 0.244 & 0.244 & $\mathrm{C}_{306}$ & 0.902 & 0.902 & 0.167 & 0.167 \\
\hline $\mathrm{C}_{104}$ & -0.900 & -0.900 & 0.013 & 0.013 & $\mathrm{C}_{401}$ & 0.894 & 0.894 & 0.141 & 0.141 \\
\hline $\mathrm{C}_{105}$ & 0.902 & 0.902 & 0.244 & 0.244 & $\mathrm{C}_{402}$ & 0.849 & 0.849 & 0.138 & 0.138 \\
\hline $\mathrm{C}_{106}$ & 0.902 & 0.902 & 0.244 & 0.244 & $\mathrm{C}_{403}$ & -0.868 & -0.868 & 0.010 & 0.010 \\
\hline $\mathrm{C}_{201}$ & 0.900 & 0.900 & 0.199 & 0.199 & $\mathrm{C}_{404}$ & -0.782 & -0.782 & 0.016 & 0.016 \\
\hline $\mathrm{C}_{202}$ & 0.900 & 0.900 & 0.199 & 0.199 & $\mathrm{C}_{405}$ & -0.809 & -0.809 & 0.014 & 0.014 \\
\hline $\mathrm{C}_{203}$ & 0.872 & 0.872 & 0.196 & 0.196 & $\mathrm{C}_{406}$ & 0.838 & 0.838 & 0.137 & 0.137 \\
\hline $\mathrm{C}_{204}$ & -0.863 & -0.863 & 0.014 & 0.014 & $\mathrm{C}_{407}$ & 0.812 & 0.812 & 0.135 & 0.135 \\
\hline $\mathrm{C}_{205}$ & 0.860 & 0.860 & 0.195 & 0.195 & $\mathrm{C}_{408}$ & 0.740 & 0.740 & 0.130 & 0.130 \\
\hline $\mathrm{C}_{206}$ & 0.879 & 0.879 & 0.197 & 0.197 & $\mathrm{C}_{409}$ & 0.699 & 0.699 & 0.127 & 0.127 \\
\hline $\mathrm{C}_{301}$ & 0.902 & 0.902 & 0.167 & 0.167 & $\mathrm{C}_{410}$ & -0.560 & -0.560 & 0.033 & 0.033 \\
\hline $\mathrm{C}_{302}$ & 0.898 & 0.898 & 0.167 & 0.167 & $\mathrm{C}_{411}$ & -0.560 & -0.560 & 0.033 & 0.033 \\
\hline $\mathrm{C}_{303}$ & 0.901 & 0.901 & 0.167 & 0.167 & $\mathrm{C}_{412}$ & 0.160 & 0.160 & 0.086 & 0.086 \\
\hline
\end{tabular}

Table 5: Sustainable development level of subsystems.

\begin{tabular}{|c|c|c|c|c|c|c|c|c|}
\hline \multirow{2}{*}{ Time } & \multicolumn{2}{|c|}{ Resource system } & \multicolumn{2}{|c|}{ Economic system } & \multicolumn{2}{|c|}{$\begin{array}{l}\text { Environmental } \\
\text { system }\end{array}$} & \multicolumn{2}{|c|}{ Social system } \\
\hline & Chengmai & Baisha & Chengmai & Baisha & Chengmai & Baisha & Chengmai & Baisha \\
\hline 2011 & 2.071 & & 2.078 & & 0.469 & & 1.468 & \\
\hline 2012 & 2.018 & & 1.346 & & 1.312 & & 1.417 & \\
\hline 2013 & 1.927 & 0.518 & 1.618 & 0.905 & 1.937 & 0.251 & 1.971 & 0.268 \\
\hline 2014 & 1.874 & 0.716 & 1.930 & 0.490 & 2.473 & 0.450 & 2.171 & 0.779 \\
\hline 2015 & 1.978 & 0.945 & 2.309 & 0.673 & 2.814 & 0.599 & 2.364 & 0.888 \\
\hline 2016 & 2.133 & 1.163 & 2.718 & 0.924 & 2.996 & 0.985 & 2.609 & 1.123 \\
\hline 2017 & & 1.375 & & 1.334 & & 1.669 & & 1.259 \\
\hline 2018 & & 1.284 & & 1.675 & & 2.045 & & 1.684 \\
\hline
\end{tabular}

Table 6: Coordination degree.

\begin{tabular}{lllllllll}
\hline Region & 2011 & 2012 & 2013 & 2014 & 2015 & 2016 & 2017 & 2018 \\
\hline Chengmai & 0.531 & 0.812 & 0.908 & 0.857 & 0.839 & 0.842 & & \\
Baisha & & & 0.650 & 0.837 & 0.851 & 0.913 & 0.895 & 0.841 \\
\hline
\end{tabular}


3.2.3 Development trend analysis

According to Table 5, the coordination degrees for both Chengmai County and Baisha County rise significantly from 0.531 in 2011 to 0.908 in 2013 and from 0.650 in 2013 to 0.841 in 2018 , respectively, after the planned construction is completed. The state of coordinated development tends to be stable, and the coordination between the subsystems has been effectively improved, as shown in Fig. 2.

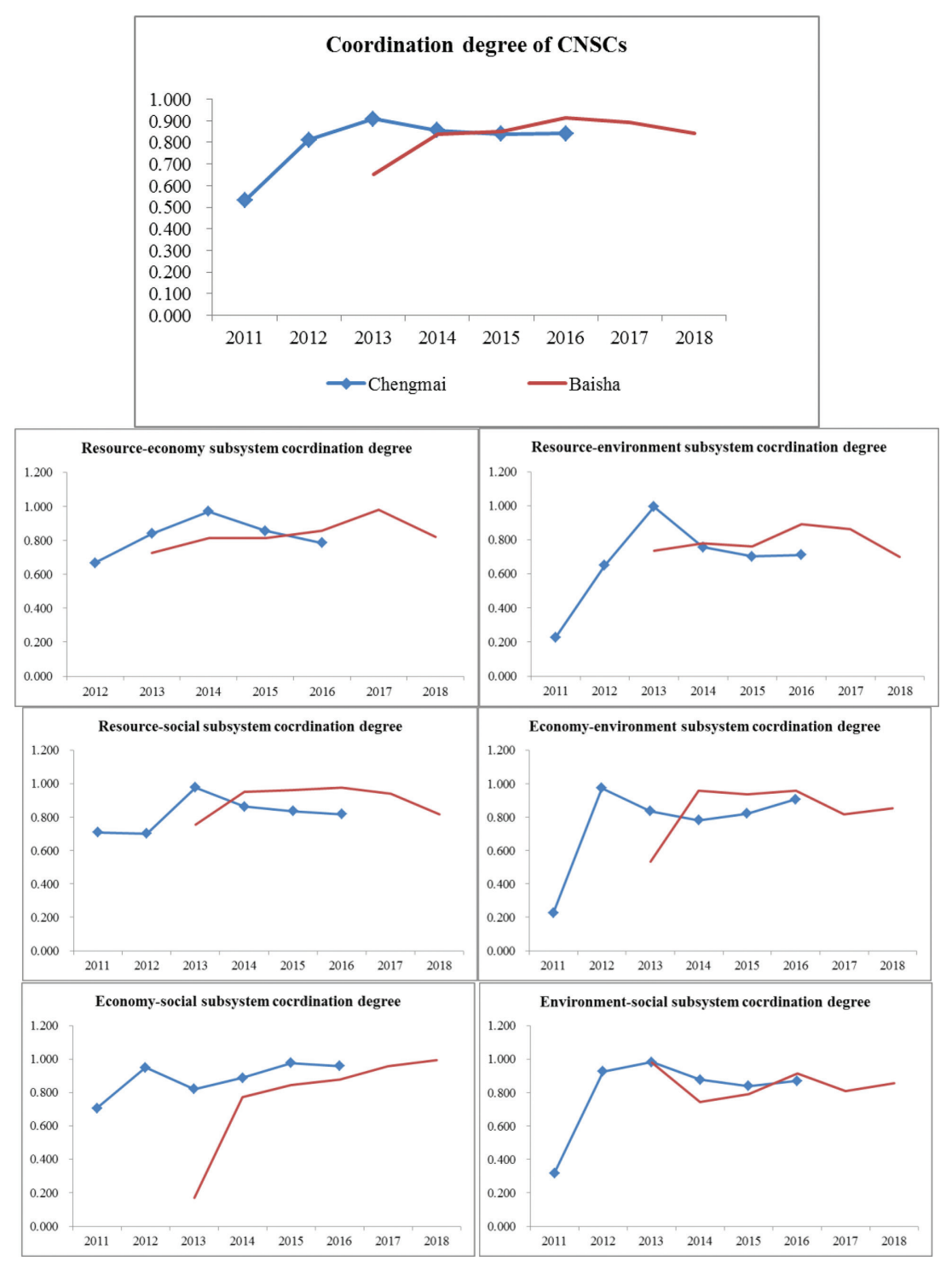

Figure 2: 2011-2018 cooperation level of National Sustainable Communities in Hainan Province. 


\section{CONCLUSIONS}

In the 1980s, China started its environmental protection policies and sustainable development strategy. CNSCs, as the primary national program for comprehensive demonstration of sustainable development, achieved an increasingly significant progress since 1986 and lack of a set of appropriate evaluation methodology.

In this article, the concept of coordination degree for CNSCs was proposed, an evaluation index system for coordination degrees of CNSCs was set up and a hierarchy for coordination degrees to evaluate sustainable development levels was presented (e.g. see Tables 1 and 2). Besides, the evaluation index system for coordination degrees of CNSCs is based on the resource, environment, economic and social subsystems, which can identify the main factors that affect coordinated development of CNSCs and can also weaken the influences caused by the differences in economic and social levels between different regions from the results of evaluation and comparison. The evaluation model for coordination degree of CNSCs has good comparability and operability and can provide decision support for evaluation of coordinated development ability, improvement of management level and promotion of construction experiences of CNSCs.

CNSCs have already developed into an enormous network platform for sustainable communities (e.g. see Fig. 1), which distribute in different regions and include various development types. To achieve coordinate development among resources, economy, environment and society is the objective for CNSCs in the future. At last, some policy implication for CNSCs was presented: (1) stimulate sustainable technology innovation and application in CNSCs; (2) encourage CNSCs to explore environmental governance innovation mechanism; (3) attach great importance to the undeveloped and resources-rich region; (4) promote social participation in the planning and construction of CNSCs.

\section{ACKNOWLEDGEMENTS}

This study is supported by Key Project of National Science and Technology Support Program 'Green Ecological Village Planning and Construction Monitoring Technology Research and Demonstration' (2014BAL04B03-3).

\section{REFERENCES}

[1] Administrative Center for China's Agenda 21, Introduction to sustainable communities, available at http://www.acca21.org.cn/local/eindex.htm. (accessed 16 August 2015).

[2] Department of Rural and Social Development of Ministry of Science and Technology \& Administrative Center for China's Agenda 21, Study and practice of the China National Sustainable Communities, Social Sciences Academic Press: Beijing, 2006.

[3] He, G.H. \& Liu, X.M., Construction management reformation and innovation of China National Sustainable Communities, Social Sciences Academic Press: Beijing, 2012.

[4] Wu, J.X. \& Wang, X.M., Actions of low-carbon construction for cities responding to climate change impacts in China, Proceedings of the 2011 World Sustainable Building Conference, Helsinki, Finland, 2011.

[5] Sadownik, B. \& Jaccard, M., Sustainable energy and urban form in China: the relevance of community energy management. Energy Policy, 10(4), pp. 520-527, 2014.

[6] Hua, H. \& Xiong, Y.H., Research on Assessment of Urban Transportation Low-carbonization Development, 2013 International Conference on Materials, transportation and Engineering (CMTEE 2013), Taichung, Taiwan, 2013. 
[7] Bicik, V., Holub, O. \& Marik, K., Platform for coordination of energy generation and consumption in residential neighborhoods. Innovative Smart Grid Technologies (ISGT Europe), 3rd IEEE PES International Conference and Exhibition, pp. 1-7, 2012. http://dx.doi.org/10.1109/isgteurope.2012.6465610

[8] Zhang, X.L. \& Huang, S.L., Theory and Application on Coordination Degree of Population, Economic Development and Ecological Environment, China Environmental Science Press: Beijing, pp. 23-26, 2008.

[9] Wang, Q.H. \& Yang, S.H., An approach to evaluation of sustainability for Guangzhou's urban ecosystem. International Journal of Sustainable Development \& World Ecology, 10(1), pp. 69-81, 2003.

http://dx.doi.org/10.1080/13504500309469787

[10] Zhang, R., An empirical study on the correlation and coordination degree of linkage development between manufacturing and logistics. Journal of Software, 12(7), pp. 2800-2807, 2012.

http://dx.doi.org/10.4304/jsw.7.12.2800-2807

[11] Soubbotina, T.P., Beyond economic growth: an introduction to sustainable development (Second Edition), World Bank Institute, 2004.

[12] Roseland, M., Sustainable community development: integrating environmental, economic, and social objectives. Progress in planning, 54(2), pp. 73-132, 2000. http://dx.doi.org/10.1016/S0305-9006(00)00003-9

[13] Zulplpiya, M., Analysis of the ecology-economy coordination degree in Yanqi Basin, Xinjiang. China Asian Journal of Chemistry, 25(16), pp. 9034-9040, 2013.

[14] Department of Social Development of Ministry of Science and Technology, Innovation capability monitor questionnaire of China National Sustainable Communities, http://www.acca21.org.cn/local/experi/syqdev/notice20140331.htm

[15] Administrative Center for China's Agenda 21, China National Sustainable Communities' innovation capability evaluation report 2014, Science and Technology Literature Press: Beijing, 2014.

[16] Chen, H.R. \&Wang, X.M., Study of China National Sustainable Community's classification evaluation method based on clustering analysis. China Population, Resources and Environment, 20(3), pp. 149-154, 2010.

[17] Chengmai County People's Government \& Huazhong University of Science and Technology, General plan of sustainable community of Chengmai country, Hainan province(2012-2016), 2011.

[18] Baisha County People's Government \& Huazhong University of Science and Technology, General plan of sustainable community of Baisha country, Hainan province (20142018), 2013. 